Article

\title{
Laparoscopic Peritoneal Wash Cytology-Derived Primary Human Mesothelial Cells for In Vitro Cell Culture and Simulation of Human Peritoneum
}

\author{
Myriam Holl 1,2, Lucas Becker 1,3, Anna-Lena Keller ${ }^{2}$, Nora Feuerer 1,2, Julia Marzi 1,2,3, \\ Daniel A. Carvajal Berrio ${ }^{1,3}$, Peter Jakubowski ${ }^{1}$, Felix Neis ${ }^{1} \mathbb{D}$, Jan Pauluschke-Fröhlich ${ }^{1}$, Sara Y. Brucker ${ }^{1} \mathbb{D}$, \\ Katja Schenke-Layland ${ }^{1,2,3,4}$, Bernhard Krämer ${ }^{1}$ (D) and Martin Weiss ${ }^{1,2, *(D)}$
}

1 Department of Women's Health, Eberhard Karls University, 72076 Tübingen, Germany; myriam.holl@student.uni-tuebingen.de (M.H.); lucas.becker@uni-tuebingen.de (L.B.); nora.feuerer@nmi.de (N.F.); julia.marzi@uni-tuebingen.de (J.M.); Daniel.Carvajal-Berrio@med.uni-tuebingen.de (D.A.C.B.); peter.jakubowski@med.uni-tuebingen.de (P.J.); felix.neis@med.uni-tuebingen.de (F.N.); jan.pauluschke-froehlich@med.uni-tuebingen.de (J.P.-F.); sara.brucker@med.uni-tuebingen.de (S.Y.B.); kschenkelayland@me.com (K.S.-L.); bernhard.kraemer@med.uni-tuebingen.de (B.K.)

2 NMI Natural and Medical Sciences Institute, University of Tübingen, 72770 Reutlingen, Germany; anna-lena.keller@nmi.de

3 Cluster of Excellence iFIT (EXC 2180) Image-Guided and Functionally Instructed Tumor Therapies, Eberhard Karls University, 72076 Tübingen, Germany

check for updates

Citation: Holl, M.; Becker, L.; Keller, A.-L.; Feuerer, N.; Marzi, J.; Carvajal Berrio, D.A.; Jakubowski, P.; Neis, F.; Pauluschke-Fröhlich, J.; Brucker, S.Y.; et al. Laparoscopic Peritoneal Wash Cytology-Derived Primary Human Mesothelial Cells for In Vitro Cell Culture and Simulation of Human Peritoneum. Biomedicines 2021, 9, 176. https: / /doi.org/10.3390/

biomedicines 9020176

Academic Editor: Yohei Hayashi

Received: 8 January 2021

Accepted: 6 February 2021

Published: 10 February 2021

Publisher's Note: MDPI stays neutral with regard to jurisdictional claims in published maps and institutional affiliations.

Copyright: () 2021 by the authors Licensee MDPI, Basel, Switzerland. This article is an open access article distributed under the terms and conditions of the Creative Commons Attribution (CC BY) license (https:// creativecommons.org/licenses/by/ $4.0 /)$.
4 Department of Medicine/Cardiology, University of California Los Angeles (UCLA), Los Angeles, CA 90095, USA

* Correspondence: martin.weiss@med.uni-tuebingen.de; Tel./Fax: +49-7071-29-82211

Abstract: Peritoneal mucosa of mesothelial cells line the abdominal cavity, surround intestinal organs and the female reproductive organs and are responsible for immunological integrity, organ functionality and regeneration. Peritoneal diseases range from inflammation, adhesions, endometriosis, and cancer. Efficient technologies to isolate and cultivate healthy patient-derived mesothelial cells with maximal purity enable the generation of capable 2D and 3D as well as in vivo-like microfluidic cell culture models to investigate pathomechanisms and treatment strategies. Here, we describe a new and easily reproducible technique for the isolation and culture of primary human mesothelial cells from laparoscopic peritoneal wash cytology. We established a protocol containing multiple washing and centrifugation steps, followed by cell culture at the highest purity and over multiple passages. Isolated peritoneal mesothelial cells were characterized in detail, utilizing brightfield and immunofluorescence microscopy, flow cytometry as well as Raman microspectroscopy and multivariate data analysis. Thereby, cytokeratin expression enabled specific discrimination from primary peritoneal human fibroblasts. Raman microspectroscopy and imaging were used to study morphology and biochemical properties of primary mesothelial cell culture compared to cryo-fixed and cryo-sectioned peritoneal tissue.

Keywords: mesothelial cells; primary cell culture; in vitro cell culture; 2D/3D cell culture model; human peritoneum; laparoscopy; wash cytology; isolation methodology

\section{Introduction}

Human peritoneal mesothelial cells form monolayers and face the mucosa of the peritoneal cavity. They grow on a thin basement membrane (peritoneum), connected with tissue stroma (collectively referred to as the serosa). Peritoneal mesothelial cells surround internal organs, form a barrier, and are the first line of defense. They ensure a protective, slippery and non-adhesive surface to facilitate the non-viscous movement of inner organs by the secretion of peritoneal fluid containing nutrients, phospholipids, surface glycosaminoglycans such as the polysaccharide hyaluronan [1]. The peritoneum 
is an important immunological interface, continuously recruiting leucocytes from the blood by cytokines and chemokines. Under physiological conditions, $50-90 \%$ of the peritoneal leucocyte population represents monocytes and macrophages, ensuring the defense of pathogens, clearance of apoptotic cells and regulating extracellular matrix (ECM) composition and sensing [2]. In light of peritoneal injury, mesothelial cells divide, transform into spindle-shaped cells and migrate to the wound area when activated. The mesothelial healing processes arise diffusely across the injured surface, in contrast to fibroblasts, which start to grow from wound edges [3].

If the physiological homeostasis fails, several peritoneal diseases may arise. Peritoneal injury and inflammation often form symptomatic and painful adhesions between serosal surfaces by edema and increased fibrogenic exudates [2,4-6]. Besides serious disorders of organ function, the formation of peritoneal adhesions is responsible for $15-20 \%$ of infertility cases after gynecologic surgery [7]. The development of intraperitoneal fibrosis during long-term peritoneal dialysis (PD) is a leading problem for the therapy of chronic kidney failure [8]. Neoplastic spreading along the peritoneum of either primary neoplasms from mesothelial cells (mesothelioma) or cancer cells from extraperitoneal (e.g., colorectal cancer and breast cancer) and intraperitoneal (e.g., ovarian cancer) lesions is a crucial factor for the oncological outcome [9]. Besides malignant cell growth, the peritoneum is frequently involved in the pathological appearance of benign ectopic cells such as endometriosis.

All of these diseases have a serious clinical impact; however, the underlying pathogenesis for each is, by far, not fully understood, and effective treatment procedures are mostly pending. Therefore, the characterization and analysis of peritoneal tissue cells have become an increasing research focus. The sufficient isolation and cultivation of primary human mesothelial cells from the peritoneum offer multiple possibilities to investigate physiology, pathogenesis and drug testing in conventional 2D in vitro models as well as in vivo like fluidic 3D platforms. Different isolation methods for human mesothelial cells were established over the past years. However, most of the widely used methods like cell isolation from omentum tissue samples face several disadvantages, such as heavy fibroblast (F) contamination, as well as limited proliferation ability and early senescence of cells $[10,11]$. Depending on the density of blood vessels within the tissue sample, contamination with microvascular endothelial cells and consecutive distortion of experimental results is likely $[12,13]$. Other working groups described the isolation of human mesothelial cells from irrigation fluid after PD. This simple method allowed fast and easily reproducible isolation of mesothelial cells; however, cells of chronic PD patients showed several degenerative changes (enlargement, multivacuolation and reduced function of cell organelles) due to the underlying disease and the long-time exposure to PD solution and its ingredients $[14,15]$. Here we report a new and easily reproducible isolation method of peritoneal primary human mesothelial cells from peritoneal wash cytology (PWC). The established method allows long-term cultivation with the highest purity of mesothelial cells. Cells were deeply characterized by immunofluorescence (IF-) staining, flow cytometry, Raman microspectroscopy and Raman imaging.

\section{Materials and Methods}

\subsection{Isolation of PWC-Derived Primary Mesothelial Cells}

PWC was obtained from consenting patients undergoing elective laparoscopic surgery at the Department of Women's Health in Tübingen. To increase cell adherence, the culture flask was coated with $0.1 \%$ gelatin diluted in sterile water. T75 cell culture flasks (Greiner bio-one, Frickenhausen, Germany) were coated with $0.1 \%$ gelatin from bovine skin (Typ B powder, Sigma-Aldrich, Darmstadt, Germany) diluted in sterile water. Sterile phosphatebuffered saline (PBS) (Dulbecco's phosphate-buffered saline, 14190-094, ThermoFisher, Schwerte, Germany) was used for all washing steps. An amount of $5 \mathrm{~mL}$ of $0.1 \%$ gelatin was added to a T75 cell culture flask. The flask was shaken gently until the whole bottom was covered with liquid. The flask was stored at $4{ }^{\circ} \mathrm{C}$ and incubated for $2 \mathrm{~h}$. After 
incubation time, the supernatant was removed. The flask was washed with PBS two times. The coated flask can be stored at $4{ }^{\circ} \mathrm{C}$ for up to 5 days until usage.

PWC was taken under sterile conditions during otherwise indicated laparoscopic surgeries at the Department of Women's Health in Tübingen between February and November 2020 after written informed consent of the patients. The Ethical Committee of the Medical Faculty of the Eberhard-Karls-University Tübingen approved the scientific use of the tissue of the Medical Faculty of the Eberhard-Karls-University Tübingen (649-2017BO2, approval: 12.01.2018 and 495/2018BO2, approval: 19.10.2018).

Isolated human peritoneal mesothelial cells were cultured in DMEM/F-12 + GlutaMAX (21331020, ThermoFisher, Schwerte, Germany) containing 10\% Fetal Bovine Serum (FBS, 10270-106, ThermoFisher, Schwerte, Germany), 1\% Penicillin/Streptomycin (15140122, ThermoFisher, Schwerte, Germany), 1\% L-Glutamine (25030-024, ThermoFisher, Schwerte, Germany). The cells were cultured at $37^{\circ} \mathrm{C}$ and $5 \% \mathrm{CO}_{2}$. Confluent cells were washed with PBS and incubated with $5 \mathrm{~mL}$ of Trypsin-EDTA (0.05\%) (Trypsin- Ethylenediaminetetraacetic acid, 25300-054, ThermoFisher, Schwerte, Germany) at $37^{\circ} \mathrm{C}$ and $5 \% \mathrm{CO}_{2}$ until cells lose adherence. $7 \mathrm{~mL}$ of culture medium was added, transferred to a falcon tube and centrifuged at $300 \times g$ for $3 \mathrm{~min}$. After removing the supernatant, cells were resuspended in $4 \mathrm{~mL}$ of fresh prewarmed culture medium and seeded again. Cell culture was observed by light microscopy (EVOS XL Core Cell Imaging System, ThermoFisher, Bothell, WA, USA).

\subsection{Isolation of Primary Human Peritoneal Fibroblasts}

Fibroblasts were isolated from peritoneal tissue samples obtained from consenting patients that were undergoing a cesarean. The Ethical Committee of the Medical Faculty of the Eberhard-Karls-University Tübingen approved the scientific use of the tissue of the Medical Faculty of the Eberhard-Karls-University Tübingen (649-2017BO2, approval: 12.01.2018). The tissue sample was washed two times with PBS. After removal of fatty tissue and blood vessels, the sample was prepared according to Takashima et al. [16]. Small slices were placed into a 6-well plate and covered with 1 to $1.5 \mathrm{~mL}$ of culture medium (MEM, Minimum Essential Media, 31095029, ThermoFisher, Schwerte, Germany), containing 10\% FBS, $1 \%$ Penicillin/Streptomycin, 1\% L-Glutamine. After 7 days, cells were detached with $0.05 \%$ Trypsin/EDTA and transferred to a T75 culture flask.

\subsection{Primary Human Peritoneal Tissue Samples}

Peritoneal tissue samples were obtained from consenting patients undergoing elective cesarean section at the Department of Women's Health in Tübingen. The sample was stored and transported at $4{ }^{\circ} \mathrm{C}$ in DMEM/F-12 cell culture media for further processing within $6 \mathrm{~h}$. The Ethical Committee of the Medical Faculty of the Eberhard-Karls-University Tübingen approved the scientific use of the tissue of the Medical Faculty of the Eber-hardKarls-University Tübingen (495/2018BO2, approval: 19.10.2018)

\subsection{HaCat (Primary Human Keratinocyte Cells) Culture, BJ Fibroblasts (Primary Human Fibroblasts)}

HaCats (Primary human keratinocyte cells, CLS, 300493) and BJ fibroblasts (primary human fibroblasts, ATCC CRL-2522) from human skin were cultured in DMEM + GlutaMAX (31966021, ThermoFisher, Schwerte, Germany) containing 10\% FBS, 1\% Penicillin/Streptomycin and 1\% L-Glutamine.

\subsection{Immunofluorescence}

Isolated mesothelial cells at passage $1-4$ and isolated fibroblasts at passage $2-5$ were used for immunofluorescence analysis. Three independent experiments were performed using cells of different patients. $1 \times 10^{5}$ mesothelial cells were seeded at gelatin-coated dishes ( $\mu$-Dish $35 \mathrm{~mm}$, low, ibidi) according to the given instructions. Fibroblasts were seeded with $5 \times 10^{4}$ cells per dish. After $24 \mathrm{~h}$, cells were washed and fixed in $4 \%$ Paraformaldehyde (PFA, P6148, Sigma-Aldrich, Darmstadt, Germany) for $10 \mathrm{~min}$ at $37^{\circ} \mathrm{C}$. Cells were permeabilized with 0.1\% Triton-X 100 (3051.3, ROTH, Karlsruhe, Germany) for $15 \mathrm{~min}$ at room 
temperature, followed by blocking in $2 \%$ bovine serum albumin (BSA, 8076, Karlsruhe, Germany) in order to reduce nonspecific binding for $60 \mathrm{~min}$. Afterward, the cells were incubated with the primary antibodies, listed in Table 1 , diluted in $0.1 \%$ BSA overnight at $4{ }^{\circ} \mathrm{C}$.

Table 1. Mesothelial cell characterization.

\begin{tabular}{ccccc}
\hline Primary Antibody & IgG Source & Dilution & Application & Company \\
\hline Cytokeratin-broad spectrum & Mouse (IgG1) & $1: 100$ & IF & Zytomed, Berlin, Germany \\
\hline Fibronectin & Rabbit & $1: 100$ & IF & Abcam, Berlin, Germany \\
\hline Calretinin & Mouse (IgG2b) & $1: 100$ & IF & Santa Cruz, Dallas, USA \\
\hline Wilms' tumor protein & Rabbit & $1: 100$ & IF & Santa Cruz, Dallas, USA \\
\hline
\end{tabular}

Subsequently, samples were incubated with the appropriate secondary antibodies (AlexaFluor 647 anti-rabbit IgG, AlexaFluor 488 anti-mouse IgG1 and AlexaFluor 488 anti-mouse IgG2b (1:1000 diluted in 0.1\% BSA; Thermo Fisher Scientific)) for $45 \mathrm{~min}$ at room temperature, protected from light. Finally, nuclei were stained with Hoechst 33,342 (R37605, ThermoFisher, Schwerte, Germany) according to the given instructions, for $20 \mathrm{~min}$ in the dark. Samples were analyzed using a fluorescence microscope (Cell Observer, Carl Zeiss AG, Oberkochen, Germany).

\subsection{Flow Cytometry}

For flow cytometric analysis, cells were prepared in the following manner: Mesothelial cells (at passage one or two), fibroblasts (at passage four to six), BJ fibroblasts and HaCats were used. Cells were harvested with trypsin and EDTA $\left(0.05 \%, 10 \mathrm{mM}\right.$ at $37^{\circ} \mathrm{C}$ for $\left.5 \mathrm{~min}\right)$ and centrifuged at $300 \times g$ for $3 \mathrm{~min} .5 \times 10^{5}$ cells were resuspended in $1 \mathrm{~mL}$ washing buffer ( $2 \%$ heat-inactivated FCS, $0.05 \mathrm{mM}$ EDTA and $0.05 \% \mathrm{NaN}_{3}$ in PBS, $\mathrm{pH}=7.4$ ) and centrifuged at $300 \times g$ for $5 \mathrm{~min}$. Nonspecific binding sites were blocked using $10 \%$ human male serum (diluted in washing buffer) for $20 \mathrm{~min}$ at $20-23{ }^{\circ} \mathrm{C}$. Cells were centrifuged again at $300 \times g$ for $5 \mathrm{~min}$. The supernatant was removed. Each pellet was resuspended in $250 \mu \mathrm{L}$ BD Cytofix/-perm (Fixation/Permeabilization Solution Kit, 554714, BD Bioscience, Heidelberg, Germany) and incubated for $20 \mathrm{~min}$ on ice in the dark. Cells were centrifuged at $300 \times \mathrm{g}$ for $5 \mathrm{~min}$ at $4{ }^{\circ} \mathrm{C}$. Pellets were washed two times with BD Perm/Wash (Fixation/Permeabilization Solution Kit, 554723, BD Bioscience, Heidelberg, Germany). The cytokeratin antibody (cytokeratin antibody, anti-human, FITC, REAfinity, clone REA831, 130-112-931, miltenyibiotec, Bergisch Gladbach, Germany) was diluted 1:50 in water containing 10\% BD Perm/Wash and 10\% human serum. Cells were incubated for $30 \mathrm{~min}$ on ice in the dark and afterward washed with BD Perm/Wash and resuspended in $100 \mu \mathrm{L}$ washing buffer. Cells were immediately analyzed using a BD FACSFortessa instrument (BD Bioscience, Heidelberg, Germany) with FACS DIVA software v9 (BD Biosciences, Heidelberg, Germany). Data were analyzed using FlowJo software v10 (FlowJo LLC, Ashland, VA, USA). Forward- and side-scatter (FSC-H and SSC-H) characteristics were used to exclude dead cells. Forward scatter area and height (FSC-A and FSC-H) characteristics were used to exclude cell doublets (see Figure S2).

\subsection{Raman Analysis}

Mesothelial cells isolated from PWC (MC-cc) at passage one to two were seeded with $2 \times 10^{5}$ cells per (gelatin-coated) dish ( $\mu$-Dish $35 \mathrm{~mm}$, high glass bottom, 81158, ibidi, Gräfelfing, Germany). After two days of culture, cells were fixed in $4 \%$ PFA at $37^{\circ} \mathrm{C}$ for 15 min prior to Raman measurements. Cryopreserved human tissues of the peritoneum (MC-cryo) were cut (10 $\mu \mathrm{m}$ thickness) and collected on glass coverslips. Prior to Raman imaging, tissue sections were washed with PBS for $10 \mathrm{~min}$. Tissues and fixed cells were covered in PBS during the entire Raman measurement to prevent sample burning and dehydration. Spectral mapping was performed on a customized upright WITec alpha300 
R Raman system (WITec GmbH, Ulm, Germany) equipped with a green laser (532 nm) and a CCD spectrograph with a grating of $600 \mathrm{~g} / \mathrm{mm}$. Raman images were acquired at three different positions for MC-cc $(n=3)$ and MC-cryo $(n=2)$ at a laser power of $57 \mathrm{~mW}$, an integration time per spectrum of $0.05 \mathrm{~s}$ and a pixel resolution of $1 \times 1 \mu \mathrm{m}$ using a $63 \mathrm{x}$ dipping objective (N.A. 1.4; Olympus, Tokyo, Japan)).

Raman image analysis of the spectral maps was performed with the software Project Five version 5.2; Software for image editing and image processing (WITec GmbH, Ulm, Germany). Raman data were subjected to cosmic ray removal, polynomial baseline correction to remove the glass background, and intensity normalization (area to 1). To analyze Raman image maps, true component analysis (TCA) was used at the spectral range of $700-1800 \mathrm{~cm}^{-1}$. In brief, TCA allows for the identification of spectral components dominating the spectral map. As a non-negative matrix factorization-based multivariate data analysis tool, this method defines similar spectra occurring in the whole scan as the same component and identified all pixels that provided these spectral characteristics in a falsecolor intensity distribution heatmap. TCA allowed preselecting regions of interest (ROI) with similar spectral information representing nuclei, ECM, and lipids for both 2D cell culture and cryosections, which were extracted for further in-depth analysis of the molecular composition by principal component analysis (PCA) using Unscrambler X10.5 (Camo Software AS, Oslo, Norway). In brief, PCA is a classic multivariate data analysis tool for reducing the dimensionality of spectral data sets, increasing interpretability but minimizing information loss on a vector-based approach. By axis-rotation, a new set of axes, so called principal components (PCs) containing maximal directions of variance within a dataset are created. Plotting PC values against each other allow visualization of correlation and separation of two or more data sets. Underlying spectral differences can be interpreted based on the corresponding loading plot.

\subsection{Image and Data Analysis}

Statistical comparisons were performed from a minimum of three independent experiments. Data are given as mean \pm SD (Standard Deviation). Statistical analysis was performed using GraphPad Prism v8 for Windows. Immunofluorescence images were prepared on ZEN v3.0 (blue edition, Oberkochen, Germany). Bright-field images were prepared using PowerPoint (v2019, Microsoft, Redmond, USA). FACS data were analyzed by FlowJo (software v10, LLC, Ashland, VA, USA).

\section{Results}

\subsection{Isolation Methodology and Cell Culture of PWC-Derived Mesothelial Cells}

Figure 1 summarizes the methodology that we have developed for the isolation of primary human mesothelial cells. It includes the obtaining of PWC during otherwise indicated gynecological laparoscopic surgeries of healthy women at the Department of Women's Health of the University Hospital Tübingen, Germany, after written informed consent. The scientific use of human tissue samples was approved by the institutional review board of the medical faculty of the University Hospital Tübingen (ethical vote: 649-2017BO2, approval: 12.01.2018; and 495/2018BO2, approval: 19.10.2018). The patientderived samples included eight PWC from healthy female patients with a median age of 35.8 years, average gravidity and parity of 1.5 and 0.5 , respectively (Table 1$) .6(75 \%)$ out of 8 patients were premenopausal. One patient (12.5\%) with absent menstrual bleeding $>6$ months and $<2$ months was defined as perimenopausal. Another patient $(12.5 \%)$ was after benign hysterectomy with unknown ovarian function. Samples were taken immediately after intraabdominal access to avoid any contamination with erythrocytes from abdominal bleeding. All of the surgeries were performed due to benign reasons. After inspection of the anatomical area, the pouch of Douglas was repeatedly flushed with $10-20 \mathrm{~mL}$ of conventional sterile isotonic $0.9 \%$ sodium chloride $(\mathrm{NaCl})$ solution for $30 \mathrm{~s}$ (Figure 1a). The liquid containing the detached mesothelial cells was collected with a standard syringe. The sample was stored and transported at $4{ }^{\circ} \mathrm{C}$ for further processing 
within $6 \mathrm{~h}$. We recommend processing the samples as soon as possible after surgical collecting. Intraoperative findings included peritoneal adhesions in 5 patients $(62.5 \%)$. One patient $(12.5 \%)$ suffered from deep-infiltrating endometriosis. Primary human fibroblasts (F) (used as controls) were isolated from primary human peritoneal tissue samples obtained during Caesarean section of 3 patients with the mean age of 28.7 years (Table 2).

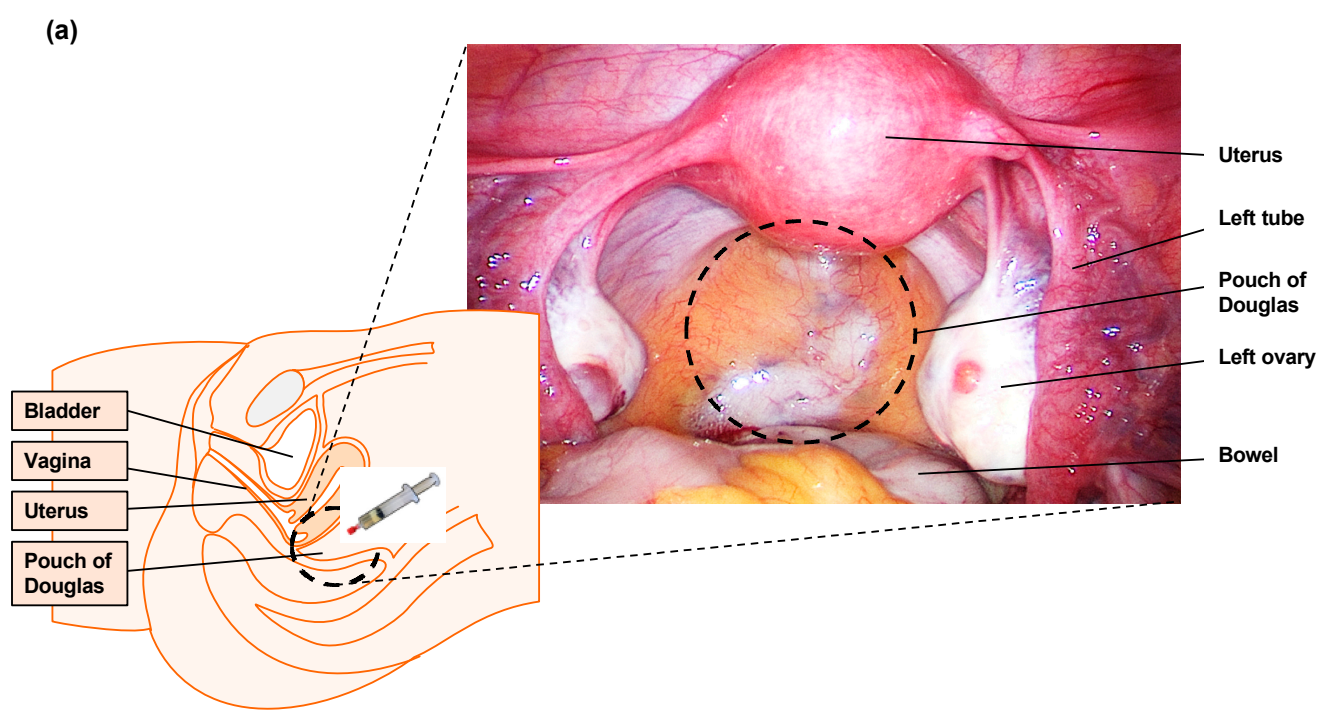

(b)

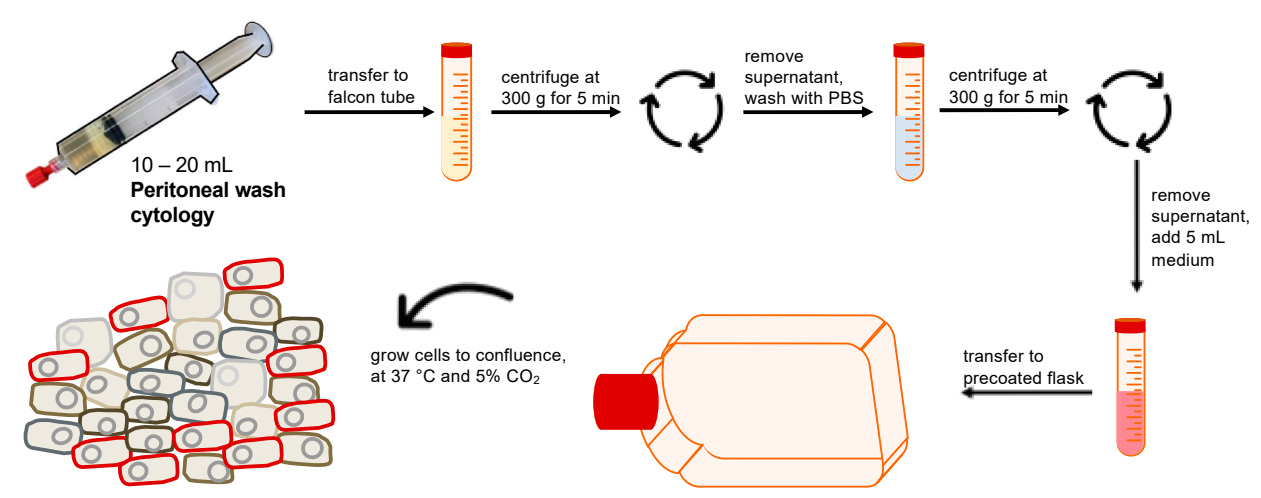

Mesothelial cell population

(c)

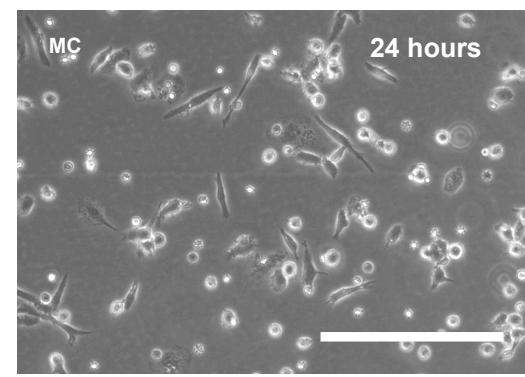

(d)

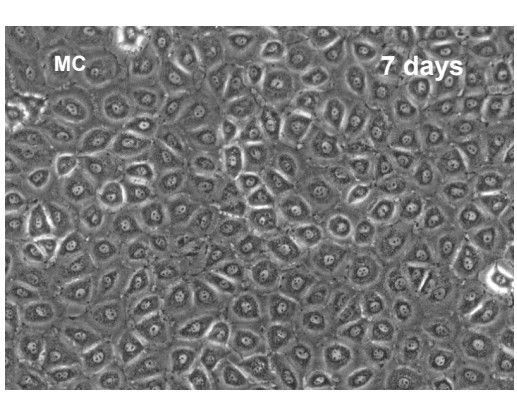

Figure 1. Isolation methodology of PWC-derived mesothelial cells. (a) Intraoperative laparoscopic view and schematic illustration of the pelvic anatomy. (b) Overview of the protocol for the isolation and cultivation of primary human peritoneal wash cytology-derived mesothelial cells prior to additional analysis. (c,d) Representative brightfield images of cultured primary human PWC-derived mesothelial cells after $24 \mathrm{~h}$ (c) and 7 days (d). Scale bar represents $200 \mu \mathrm{m}$ for both images. 
Table 2. Patient characteristics.

\begin{tabular}{|c|c|c|}
\hline & MC & $\mathbf{F}$ \\
\hline No. of patients, $n(\%)$ & $8(100)$ & $3(100)$ \\
\hline Median age, years (range) & $35.8(22-55)$ & $28.7(25-31)$ \\
\hline Gravidity, $n$ (range) & $1.5(0-5)$ & $1.0(1)$ \\
\hline Parity, $n$ (range) & $0.5(0-2)$ & $1.0(1)$ \\
\hline \multicolumn{3}{|l|}{ Ovarian function, $n(\%)$} \\
\hline premenopausal & $6(75.0)$ & $3(100)$ \\
\hline perimenopausal & $1(12.5)$ & - \\
\hline \multicolumn{3}{|l|}{ Cause for surgery } \\
\hline Hypermenorrhea/Hysterectomy & $2(25.0)$ & - \\
\hline Diagnostic/Pain & $2(25.0)$ & - \\
\hline Diagnostic/Childwish & $1(12.5)$ & - \\
\hline Cysts & $3(37.5)$ & - \\
\hline Cesarean section & - & $3(100)$ \\
\hline \multicolumn{3}{|l|}{ Intraoperative findings } \\
\hline Adhesions & $5(62.5)$ & - \\
\hline Endometriosis & $1(12.5)$ & - \\
\hline none & $2(25.0)$ & - \\
\hline
\end{tabular}

Following intraabdominal extraction, the PWC was further purified and centrifuged to remove contaminating cells and cell debris (Figure $1 \mathrm{~b}$ ). Therefore, the liquid was transferred to a sterile $50 \mathrm{~mL}$ falcon tube. Cells were spun at $300 \times g$ for $5 \mathrm{~min}$. The supernatant was removed carefully, and $10 \mathrm{~mL}$ of fresh sterile PBS$^{-}$was added. The cell pellet was resuspended gently. After that, cells were spun again at $300 \times g$ for $5 \mathrm{~min}$. Once again, the supernatant was removed. An amount of 4-5 $\mathrm{mL}$ of fresh prewarmed culture medium (DMEM/F-12 + GlutaMAX, containing 10\% fetal calf serum, 1\% PenicillinStreptomycin and 1\% L-Glutamine) was added. Optionally, cells were counted to determine cell number. The culture flask was coated with $0.1 \%$ gelatin diluted in sterile water to increase cell adherence. $7-8 \mathrm{~mL}$ of prewarmed culture medium was added to a T75 culture flask. The cell suspension was transferred to the culture flask. Cells were cultured at $37^{\circ} \mathrm{C}$ and $5 \% \mathrm{CO}_{2}$ for at least two days. After $2-3$ days, cells were carefully washed with prewarmed PBS, to remove non-adherent and dead cells. Fresh culture medium was added every $2-3$ days.

After $24 \mathrm{~h}$ of cultivation, cells showed a bi- to multipolar, elongated morphology (Figure 1c). On day three, cells appeared oval and circular (data not shown). Following this initial growth phase, cells adapted a typical cobblestone-type appearance. After four to five days, mesothelial cells revealed a homogeneous monolayer with the absence of fibroblast contamination. Depending on the seeded cell number $\left(1 \times 10^{5}-1 \times 10^{7}\right.$ cells per T75 cell culture flask), cells reached confluence after 7 to 10 days (Figure $1 \mathrm{~d}$ ). Cells were successfully cultured over five passages. Beyond this point, the mesothelial cells showed an increase in cell size and number of cell nuclei, which indicate the development of senescent-like cells. Mechanical irritation or long-time incubation with trypsin/EDTA was often followed by a loss of mesothelial cell-morphology and consecutive transformation to a fibroblast-like appearance. 


\subsection{IF-Microscopic Characterization of PWC-Derived Mesothelial Cells and Suitable Molecular} Markers to Distinguish from Peritoneal Fibroblasts

Next, we evaluated different cellular factors to specifically characterize and distinguish mesothelial cells from peritoneal fibroblasts, possibly contaminating the PWC-derived mesothelial cells. Therefore, primary mesothelial cells derived from peritoneal washcytology and tissue-derived peritoneal fibroblasts were analyzed by high-resolution IFmicroscopy following IF-staining with specific antibodies against cytokeratin, fibronectin, calretinin and WT-1 (Figure 2a-h). Mesothelial cells showed a specific and high expression of the epithelial markers cytokeratin and calretinin. The IF-signal of the intermediate filament cytokeratin seemed to increase from perinuclear to the outer cell membrane. The calcium-binding protein calretinin was also found intracellularly with a lower perinuclear IF-signal and some cells with very low overall expression. Both factors, cytokeratin and calretinin, were negative in fibroblasts, whereas fibroblasts exhibited a high expression of the glycoprotein fibronectin. Most of the mesothelial cells showed no expression of fibronectin; however, it was sporadically detectable in all PWC-derived mesothelial cell populations (Figure 2c,d). Co-staining with cytokeratin and fibronectin of co-cultured mesothelial cells and fibroblasts showed a sufficient cell type-specific and spatial distinction of the two cell types suitable for high-resolution IF-microscopy (Supplemental Figure S1). In both cell types, the nuclear transcription factor WT-1 (Wilms' tumor protein) was highly expressed within the cell nuclei. Overall, due to the highly specific, homogenous and intense expression in mesothelial cells irrespective of the passage number, cytokeratin especially was found as a suitable, reliable and simply performable marker for MC characterization and discrimination from other peritoneal cell types.

\subsection{PWC-Derived Primary Mesothelial Cells Revealed above-Average Purity}

By performing flow cytometry, the purity of PWC-derived mesothelial cell cultures was determined based on the expression of cytokeratin as a characterized mesothelial cell marker (see Figure 2). Following isolation from PWC and peritoneal tissue, the primary mesothelial cells and primary fibroblasts were harvested, formalin-fixed, and stained with specific antibodies against cytokeratin. After that, cells were analyzed by flow cytometry (Figure 3a-f,i). Flow cytometry was performed using a BD LSRFortessa cell analyzer with a $488 \mathrm{~nm}$ laser. Gates were set including 1\% of unstained cells (for detailed gating strategy, please see Supplementary Figure S3). Results from one representative experiment showed an average mesothelial cell population of $98.9 \%$ being positive for cytokeratin (Figure 3a,c,e). Fibroblasts isolated from peritoneal tissue samples, instead, showed up to $16.1 \%$ of cells positive for cytokeratin (Figure $3 b, d, f)$, which, by definition, cannot be fibroblasts. Figure $3 i$ shows the result of three independent experiments with an average of $97.7 \pm 0.7 \%$ of cytokeratin-positive cells within the PWC-derived mesothelial cells and $7.01 \pm 5.5 \%$ of cytokeratin-positive cells within the peritoneal tissue-derived primary fibroblasts (Figure 3i). Additionally, we performed cytokeratin staining followed by flow cytometry of commercially purchased keratinocyte and BJ-fibroblast cell lines to compare their purity with our isolation method. Comparable to PWC, the keratinocyte cell line showed a proportion of $99.45 \pm 0.6 \%$ cytokeratin-positive cells, whereas only $0.39 \%$ of cells of the BJ fibroblast cell line were positive for cytokeratin (Figure 3i, for detailed figures, please see Figure S3).

\subsection{Characterization of the Molecular Structure and Composition of PWC-Derived Primary Mesothelial Cells Cryo-Preserved Peritoneal Tissue Samples Using Raman Imaging}

To characterize PWC-derived primary mesothelial cells and native cryopreserved peritoneal tissue, we applied contactless and marker-independent Raman imaging and multivariate data analysis. Utilizing Raman imaging, we were able to perform morphological as well as molecular tissue analysis within the same experiment $[17,18]$. Raman spectra of primary mesothelial cell culture after PWC were acquired from three different patients after 2 days of cell culture in passage two. Additionally, we acquired Raman spec- 
tra of cryo-fixed and cryo-sectioned peritoneal tissue obtained from primary Caesarean sections of two patients at the Department of Women's Health, Tübingen. Through Raman imaging and single spectra extraction, we were able to identify and compare the molecular characteristics and localization of different cellular components.

Raman imaging and True Component Analysis (TCA) allowed us to identify ECM-like intracellular spectra (green), ECM (orange), DNA within the nuclei (blue) as well as lipids (yellow) in both, primary mesothelial cell culture as well as cryo-fixed and cryo-sectioned peritoneal tissue (Figure 4a) based on their spectral fingerprints (Figure 4b).

(a)

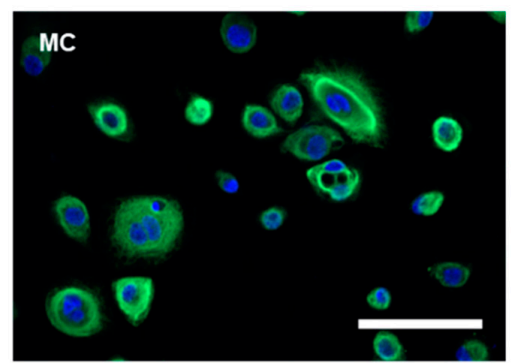

(c)

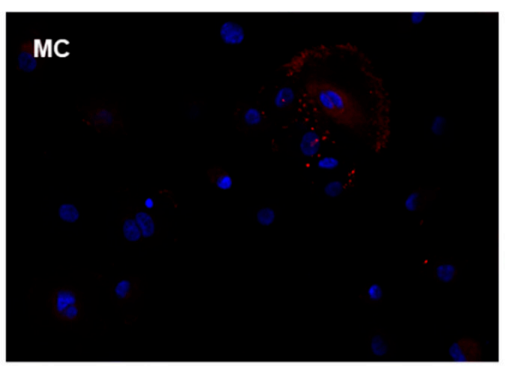

(e)

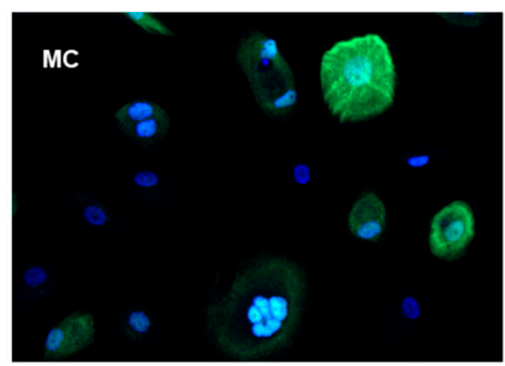

(g)

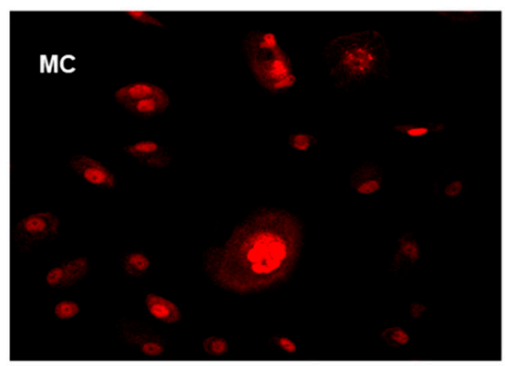

(b)

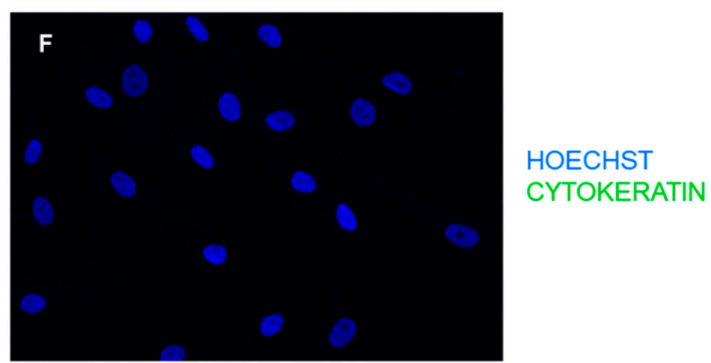

(d)

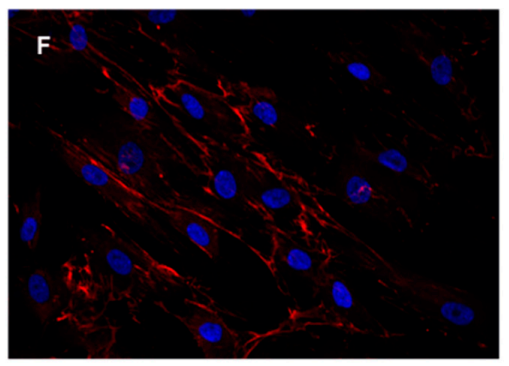

(f)

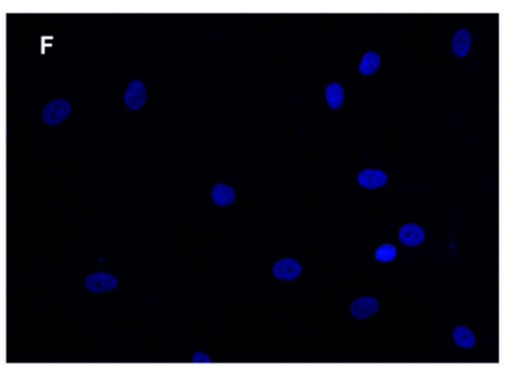

(h)

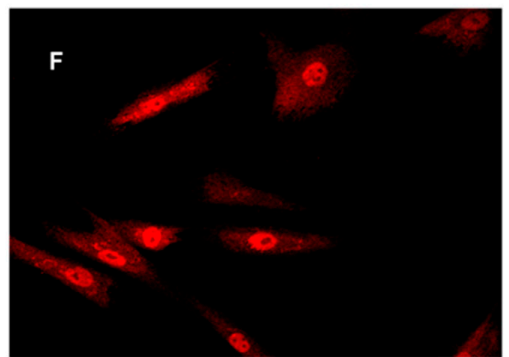

HOECHST

FIBRONECTIN

HOECHST

CALRETININ

WT-1

Figure 2. Characterization of PWC-derived mesothelial cells and distinction from peritoneal fibroblasts. Mesothelial cells (MC) were isolated from PWC, fibroblasts $(F)$ were isolated from peritoneal tissue samples. Both cell types were cultured for 3 to 4 days. Immunofluorescence staining of MC and F for cytokeratin (a,b), fibronectin (c,d), calretinin (e,f) and WT-1 (Wilms' tumor protein) (g,h) was performed. (a) MC showed a high expression of epithelial marker cytokeratin, while (b) F were found to be negative. (c) Some of MC showed a low expression of fibronectin, whereas (d) F exhibited a high expression of fibronectin. (e) MC expressed calretinin in varying intensities in contrast to (f) F, which were negative for calretinin. (g) MC and F (h) showed a high and similar expression of Wilms' tumor protein 1 (WT-1). Scale bar represents $100 \mu \mathrm{m}$. 
(a)

MC

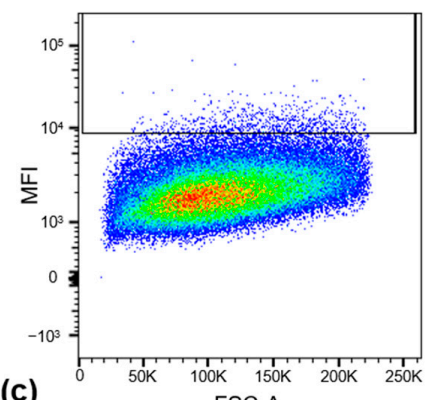

(c)

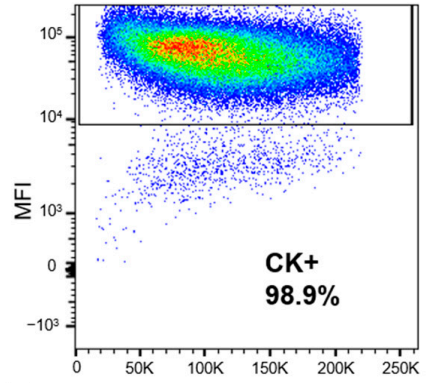

(e)

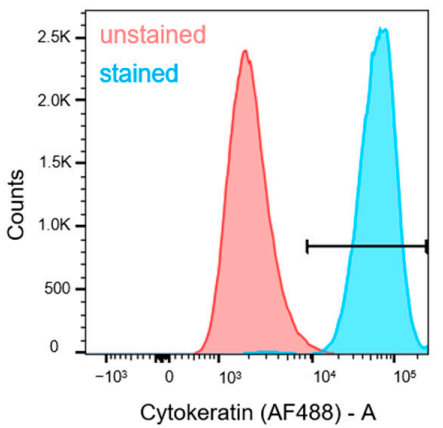

(b)

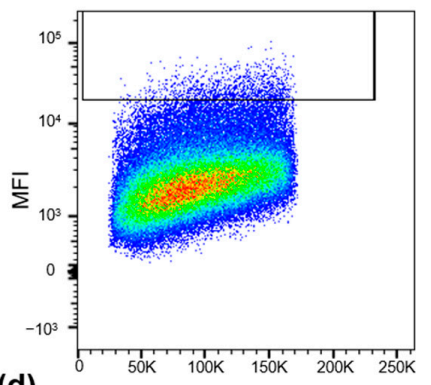

(d)

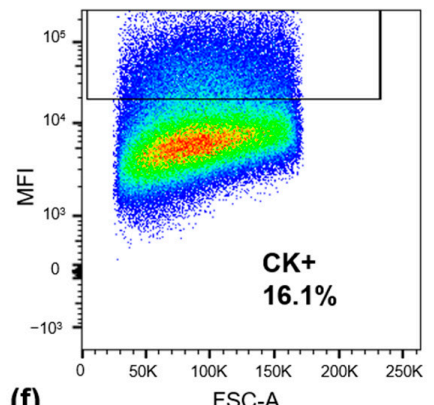

(f)

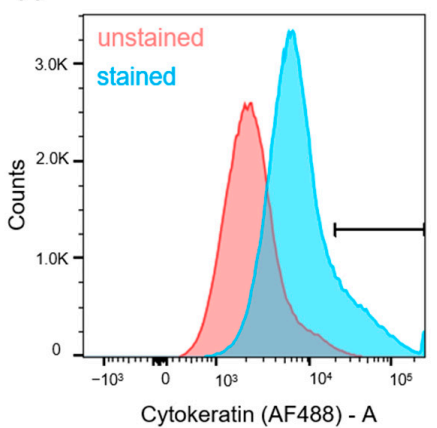

(g)

(h)
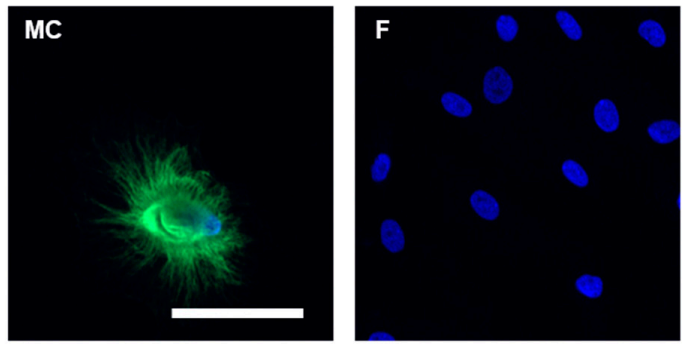

HOECHST

CYTOKERATIN

(i)

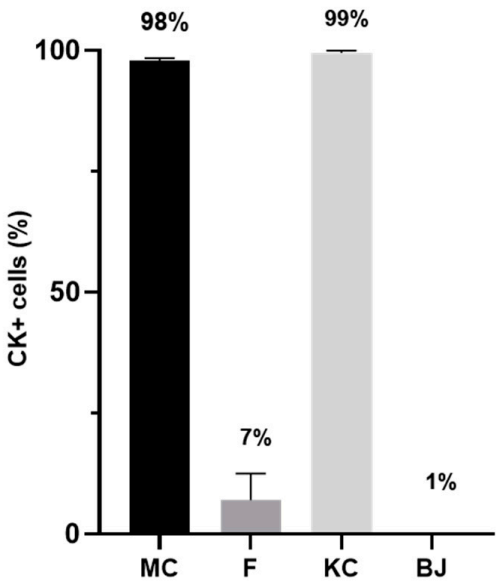

Figure 3. Determination of mesothelial cell (MC) purity by cytokeratin (CK) staining and flow cytometry. PWC-derived primary MC and peritoneal tissue-derived F, a commercially purchased keratinocyte (KC) and BJ fibroblast (BJ) cell line were stained for cytokeratin. Flow cytometry using the $488 \mathrm{~nm}$ laser of a BD LSRFortessa cell analyzer was performed to identify CK-positive $(\mathrm{CK}+)$ cells. (a,b) Mean fluorescence intensity (MFI) of unstained MC (a) and F (b) are shown. Both gates were set, including $1 \%$ of unstained cells. (c,d) Representative flow cytometry experiment. CK-positive cells are shown as FSC-A versus MFI. (c) $98.9 \%$ of the stained representative MC population was found to be cytokeratin-positive. (d) $16.1 \%$ of the representative F population expressed cytokeratin. (e,f) The histograms of unstained (red) and stained (blue) cells were compared. (e) CK-stained MC cells shifted substantially to the right, into the CK-positive gate. (f) CK-stained F population showed a small shift. (g,h) Representative IF-microscopy after CK-staining of MC (g) and F (h) in 63× magnification. (i) Mean percentage of CK-positive cells analyzed by flow cytometry and determined in three independent experiments. Results are shown as \pm standard error of mean percentage. Scale bar represents $50 \mu \mathrm{m}$. 
(a)

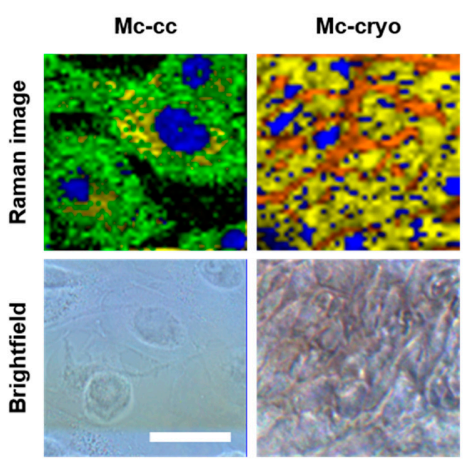

(c)

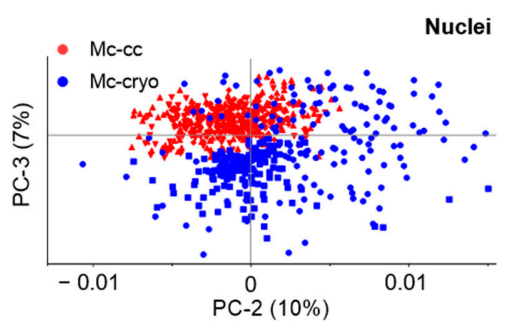

(e)

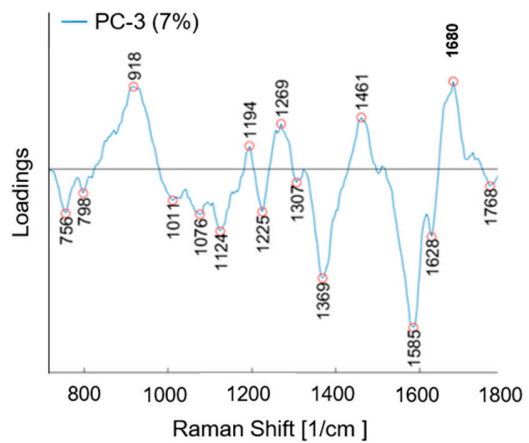

(b)

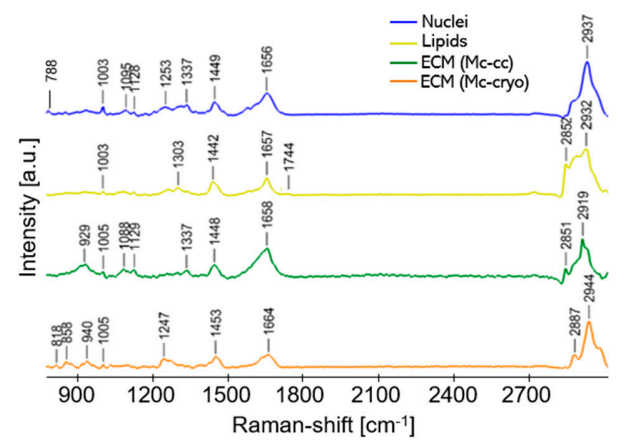

(d)

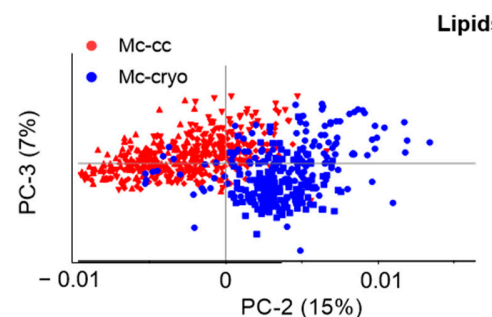

(f)

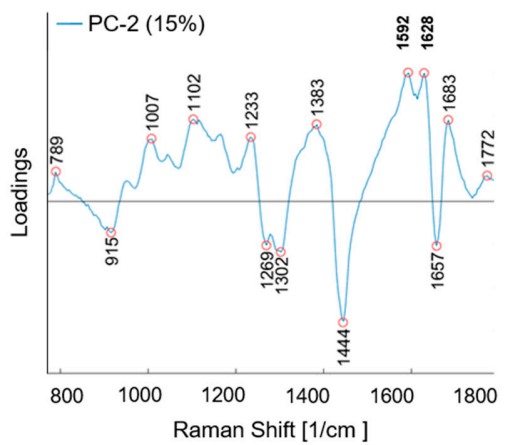

(g)

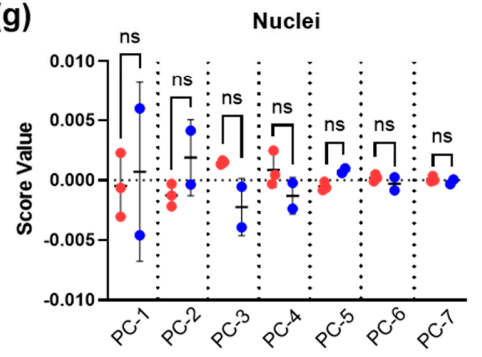

(h)

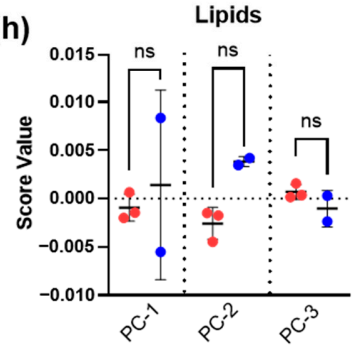

Figure 4. Raman imaging and multivariate data analysis of PWC-derived mesothelial cell culture (MC-cc) and cryo-fixed peritoneal tissue (MC-cryo). MC-cc were cultured on dishes, fixed with PFA and imaged in PBS using a customized upright WITec alpha300 R Raman system. MC-cryo were washed and imaged. MC-cc and MC-cryo were compared by multivariate data analysis with a focus on nuclei (DNA), lipids, and ECM components. (a) Representative Raman images and brightfield images of MC-cc and MC-cryo. Scale bar represents $50 \mu \mathrm{m}$. (b) Characteristic fingerprint spectra of the analyzed molecular components, utilized to identify nuclei/DNA (blue), lipids (yellow) and ECM (MC-cc, green; MC-cryo, orange) components by TCA. (c) Principal component analysis (PCA) scores plot of PC2 vs. PC3 of extracted nuclei spectra showed trends of clustering between MC-cc and MC-cryo. (d) Scores plot of PC2 vs. PC3 of extracted lipid spectra indicates a trend of clustering between MC-cc and MC-cryo. (e) Loadings plot corresponding to nuclei-specific PCA indicates peaks that explain the trend of clustering in PC-3. (f) Loadings plot of lipid-specific spectral information highlights peaks responsible for the trend of clustering in PC2. (g) DNA-specific average score values for PC1 to PC7 showed no significant difference between MC-cc and MC-cryo. (h) Lipid-specific average score values for PC1-PC3 revealed no significant difference between MC-cc and MC-cryo. Results are shown as mean \pm SD of PC score values, $n=3$ (MC-cc) $n=2$ (MC-cryo). 
Peaks related to DNA $\left(788,1095 \mathrm{~cm}^{-1}\right.$; representing O-P-O stretching, see Table 3) $[19,20]$ defined the structures detected by the first TCA component (Figure 4a, blue). Thereby, mesothelial cell culture and cryo-fixed peritoneal tissue were characterized by morphological differences in the size of nuclei (larger in mesothelial cell culture). Lipids (yellow) were detected as a second component of the TCA assigned to peaks at 1442, 1667, 1774 and $2852 \mathrm{~cm}^{-1}$ representing $\mathrm{CH} 2$ (methylene group) bending in fatty acids [21,22], unsaturated $\mathrm{C}=\mathrm{C}$ bonds [21,22], carbonyl features [23] and $\mathrm{CH} 2$ symmetric stretch of lipids [24]. The lipid component is broadly distributed between nuclei in both analyzed tissues (Figure 4a, yellow). In mesothelial cell culture, a third component showed peak assignments for ECMlike spectra of proteins indicated by peaks at 929, 1005, 1567, and $2912 \mathrm{~cm}^{-1}$ representing C-C stretching in amino acids such as proline and valine [25], phenylalanine [19], Amide I [26] and $\mathrm{CH}$ stretch of proteins [24] (Figure 4a, green). In cryopreserved tissue sections, TCA identified different ECM protein components consisting of peaks related to collagen such as 818 [27], 1247 [27] and $1453 \mathrm{~cm}^{-1}$ [25] (Figure 4a, orange).

Table 3. Identified Raman peaks $\left[\mathrm{cm}^{-1}\right]$ and their molecular assignments.

\begin{tabular}{|c|c|c|}
\hline Peaks $\left(\mathrm{cm}^{-1}\right)$ & Assignment & Reference \\
\hline 756 & Tryptophan & [31] \\
\hline 788 & O-P-O stretching & [19] \\
\hline 818 & C-C stretching in collagen & [27] \\
\hline 918 & Proline & [28] \\
\hline 929 & C-C stretching in amino acids such as proline and valine & [25] \\
\hline 1005 & Phenylalanine & [19] \\
\hline 1011 & Carbohydrates & [22] \\
\hline 1076 & C-C in lipids & [20] \\
\hline 1095 & DNA backbone & [20] \\
\hline 1124 & Lipid backbone & [28] \\
\hline 1247 & Amide III in collagen & [27] \\
\hline 1269 & C-C vibration & [30] \\
\hline 1302 & $\mathrm{CH} 2$ wagging & [32] \\
\hline 1369 & Lipids & [31] \\
\hline 1442 & C-C in fatty acids & [22] \\
\hline 1444 & $\mathrm{CH} 2$ scissoring & [29] \\
\hline 1453 & $\mathrm{CH} 3$ bending and $\mathrm{CH} 2$ scissoring in collagen & [25] \\
\hline 1592 & $\mathrm{C}=\mathrm{C}$ & [33] \\
\hline 1628 & $\mathrm{C}=\mathrm{C}$ & [34] \\
\hline 1657 & $\mathrm{C}=\mathrm{C}$ stretching & {$[21,22]$} \\
\hline 1658 & Amide I & [26] \\
\hline 1680 & Amide I & [29] \\
\hline 1774 & Carbonyl feature in fatty acids & [23] \\
\hline 2852 & $\mathrm{CH} 2$ symmetric stretch of lipids & [24] \\
\hline 2912 & $\mathrm{CH}$ stretches of proteins & [24] \\
\hline
\end{tabular}

For in depth analysis of molecular differences between mesothelial cell culture and cryo-fixed peritoneal tissue, a PCA was performed on extracted single spectra of nuclei. The PCA scores plot revealed a distinct trend of clustering between both mesothelial cell conditions for all principal component (PC) except for PC3 showing a trend of spectral 
separation (Figure 4c). According to the correlating loadings plot (Figure 4e) trends of separation are explained by peaks at 918,1269 and $1680 \mathrm{~cm}^{-1}$ contributing to mesothelial cell culture and 756, 1076, 1011, 1124, 1225, 1369, 1585 and $1628 \mathrm{~cm}^{-1}$ representing separation for cryo-fixed peritoneal tissue. The broad band at $918 \mathrm{~cm}^{-1}$ was assigned to proline [28], while $1269 \mathrm{~cm}^{-1}$ and $1680 \mathrm{~cm}^{-1}$ can be correlated to changes in Amide III and Amide I groups [29,30]. For peaks separating for cryopreserved tissue, higher tryptophan (Trp) content can be detected at $756 \mathrm{~cm}^{-1}$ [31]. Next to peaks representing C-C bond in carbohydrates (1011 cm $\mathrm{cm}^{-1}$ [22]) and lipids (1076 and $1124 \mathrm{~cm}^{-1}$ [20,28]), C-H bending vibrations are the reason for the trend of separation (1307 and $\left.1369 \mathrm{~cm}^{-1}[28,31]\right)$. Additionally, Amide I peaks representing carbonyl groups at 1585 and $1628 \mathrm{~cm}^{-1}$ are separating the two groups slightly. T-tests of mean score values were performed to analyze the significance of clustering through all PCs (Figure 4g); however, they did not show any significant differences.

Similar results were found when comparing lipid features in mesothelial cell culture and cryo-fixed peritoneal tissue by PCA (Figure 4d) and t-tests on mean score values (Figure 4h). While PC1 (scores plot not shown) was rather linked to differences between tissue donors, PC2 indicated trends of separation due to peaks in the loading plot at 1296, 1445 and $1656 \mathrm{~cm}^{-1}$ contributing to mesothelial cell culture and peaks at 1009, 1102, 1240, $1384,1589,1628$ and $1680 \mathrm{~cm}^{-1}$ for cryo-fixed peritoneal tissue samples (Figure 4f). Peak assignments within the loading plot are mainly assigned to differences in C-C vibrations $\left(1296 \mathrm{~cm}^{-1}\right.$ [30]) as well as $\mathrm{CH} 2$ wagging and $\mathrm{CH} 2$ scissoring (1302 and $1444 \mathrm{~cm}^{-1}$ [29,32]). (Figure 4f). Positive loadings of PC2 may be indicating a trend of separation for cryo-fixed peritoneal tissue revealed relatively higher Raman signals contributing from phenylalanine $\left(1007 \mathrm{~cm}^{-1}\right)$, carbohydrates $\left(1002 \mathrm{~cm}^{-1}\right)$ and Amide III $\left(1233 \mathrm{~cm}^{-1}\right)$. Additionally, peaks indicated more $C=C$ vibrations at 1592 [33] and $1628 \mathrm{~cm}^{-1}$ [34] as well as $C=O$ vibrations at $1683 \mathrm{~cm}^{-1}$. For lipid components, three principal components could be calculated and compared between the two mesothelial tissue specimens, which showed no statistically significant differences (Figure $4 \mathrm{~h}$ ).

\section{Discussion}

The human peritoneum fulfills multiple tasks to ensure the integrity of the human body. Since the peritoneum accounts for several benign and malignant diseases, the cultivation of patient-derived peritoneal tissue is important for the investigation of pathomechanisms and possible treatments. In this study, we established a new isolation method for human peritoneal mesothelial cells. In general, primarily isolated mesothelial cells from solid tissue samples are very likely to be contaminated with other cell types. Several early studies on the isolation of mesothelial cells from omental tissue samples by enzymatic degradation described a homogeneous population. Major concerns about the purity of these primary cell cultures were disproved by the examination of several cellular characteristics. In 1990, Stylianou et al. described their isolation method utilizing very low trypsin concentrations of $0.125 \% \mathrm{wt} / \mathrm{vol}$ to limit fibroblast contamination [11]. However, the influence of enzyme concentration and incubation time had a significant impact on the purity of isolated primary mesothelial cells, which challenges the method itself. To characterize the isolated mesothelial cells, they especially used IF-staining of cytokeratin and further likely specific intermediate filaments as well as electron microscopic demonstration of microvilli. Omental trypsin/ethylenediaminetetraacetic acid (EDTA) disaggregation is one of the most frequently used methods for mesothelial cells in literature [35-37]. Chung-Welch et al., in 1990, described a two-stage collagenase dissociation procedure to obtain mesothelial and endothelial cells from omental tissue [38]. Via brightfield microscopy, they show a mostly typical cobblestone-like appearance of cells after two days; however, some cells appear suspicious for fibroblasts due to a spindle-like, elongated phenotype. Interestingly, incubation with endothelial growth factor (EGF) increased the amount of fibroblast-like cells to approximately $50 \%$. 
Anatomically, mesothelial cells are connected with the basal lamina, a layer of collagen IV and laminin containing ECM, at the basal surface [9]. The submesothelial stroma consists of connective tissue consisting of collagen fibers, fibronectin, proteo- and glycosaminoglycans, (myo)fibroblasts, adipocytes as well as lymphatic tissue and (in a low density) microvessels. Generally, binding of the mesothelial cells to the basal lamina is weak and cells may have already detached due to minor injuries followed by exposed stroma. Therefore, we ensured to exclusively enroll patients with macroscopically preserved peritoneal integrity. Consequently, the collection of PWC was the very first step after entering the abdomen. Certain contamination with other stromal cell types is likely. However, a serious contamination would have been identified by an inferior ratio of cytokeratin positive and negative cells, because any of the stromal cell components (fibroblasts, lymphocytes, adipocytes and microvascular pericytes and endothelial cells) usually do express cytokeratin [10]. Due to the complete enzymatic digestion of the peritoneal tissue including the stroma, the contamination with microvascular endothelial cells is a major problem for mesothelial cell isolation from solid omental tissue [12]. Nevertheless, even in case of minor injuries of the peritoneal surface, microvascular endothelial cell contamination is highly unlikely for PWC due to shielded anatomical integrity of microcapillaries by fibroblastlike pericytes, longitudinally surrounding the microvessels and, thereby, preventing the direct contact of endothelial cells with PWC fluid [39].

Besides a considerable risk for contamination with other cell types (e.g., fibroblasts, endothelial cells), the use of solid visceral (e.g., omentum) or parietal (e.g., pelvic wall) peritoneal tissue is associated with ethical, methodological, and general scientific disadvantages. The excision of peritoneal tissue from healthy volunteers/patients is always critical due to the risk of injury, bleeding, and the damage of physiological structures. In the present study, we obtained peritoneal samples from the cutting edge during primary cesarean sections, in which the peritoneum is dissected, anyway. However, in order to ethically justify the tissue removal and the associated risks, it is usually carried out in the context of other medical indications-such as cancer surgery, or, as in our example, in the context of surgical delivery. Underlying diseases (such as cancer) or conditions of changed physiology (e.g., pregnancy) may have a critical influence on the following experiments after tissue removal [40]. Here, we established an isolation method for peritoneal mesothelial cells from laparoscopic PWC. Primarily, the method aims to enable the easy, time and cost sparing isolation of healthy mesothelial cells to generate physiological 2D and 3D cell culture models. Therefore, it is especially sufficient for human subjects with preserved peritoneal integrity. Healthy patients undergoing diagnostic laparoscopy for reasons of intra-abdominal pain or fertility diagnostics were enrolled. Our methodology is a further development based on the mesothelial cell isolation from irrigation fluid after PD, which was established by several working groups $[14,15,41]$. Besides the simplicity and high reproducibility of this method, cells of chronic PD patients showed several degenerative changes (enlargement, multivacuolation and reduced function of cell organelles) triggered by the underlying disease and the long-time exposure to PD solution and its ingredients, which could critically interfere with following experiments. Due to the often diagnostic character of laparoscopies, severe pathologies can be excluded even before the non-invasive sample collection by PWC.

In the present study, we confined our characterization and flow cytometric analysis to cytokeratin, which demonstrated to be highly specific for the distinction between the epithelial mesothelial cells and mesenchymal fibroblasts as other working groups have proven before [9,42-44]. The efficiency and reliability of cytokeratin staining were far superior to other intracellular and apparently specific molecules (Figure 2). Identifying mesothelial cells by cytokeratin and calretinin expression was previously shown by Yang et al. [45]. Indeed, also in our experiments, calretinin was specific for mesothelial cells and could be identified irrespective of passage number. However, the expression of the calcium-binding protein was found to be very inconstant and partly inexistent (Figure 2e,f). Fibronectin, however, was often described as a sufficient marker for the characterization of 
ECM producing mesenchymal cells, especially fibroblasts [11,41,46,47]. As other working groups before, we showed that mesothelial cells, which are known to produce ECM to a certain extent, were partly positive for fibronectin, too [11,48]. Data from flow cytometry showed that mesothelial cells isolated from PWC exhibited a very high mean purity of $97.67 \pm 0.67 \%$ (Figure 3). Compared to the abundance of studies, characterizing their isolates by microscopic procedures, flow cytometry as high-throughput analysis of thousands of single cells has considerable advantages in this context and verified a nearly pure mesothelial cell population (Figure 3). The isolated cells showed a bipolar and elongated morphology during the initial growth phase (Figure 1). After three days of culture, cells adapted an oval and circular appearance and finally revealed a cobblestone-type structure when reaching confluency after 7-10 days. Moreover, cell morphology as well as the expression of the specific markers, was stable over at least four to five passages. Other working groups described a similar morphological development over time $[11,49,50]$. Mesothelial cells from omental tissue isolated by Styliano et al. reached confluency after $18 \pm 1$ days and were successfully cultured up to six passages [11]. Mesothelial cells isolated from spent dialysis fluid of PD patients developed a heterogeneous population. Cells need a long time to reach confluency [41,47]. Presumably, mesothelial cells were pre-exposed to systemic influences and dialysate, which results in possibly damaged cells.

Raman microspectroscopy and multivariate data analysis have been used for the contact and marker independent analysis and biochemical characterization of various human cell types and tissues $[17,18,51,52]$. Here, we characterized and compared the morphology and biochemical properties of 2D cell culture of isolated mesothelial cells from PWC and cryofixed solid peritoneal tissue (Figure 4). Compared to previous studies mostly using brightfield and IF-microscopy, the multiparametric Raman imaging is of great advantage to simultaneously determine morphological and functional characteristics in living and cryofixed tissue. Previously, Parlatan et al. in 2019 evaluated Raman spectroscopy as a non-invasive diagnostic tool for peritoneal endometriosis [53]. In 2016, Gaifulina et al. characterized the mesothelial cell layer of visceral peritoneum mainly by defining connective tissue (collagen) and nuclei [54]. To our best knowledge, this is the first study deeply characterizing biochemical and morphological aspects of human peritoneal tissue by Raman microspectroscopy and imaging. The assessment of in vitro cultivated mesothelial cells and the mesothelial layer of cryofixed peritoneum in the present study showed a size difference of nuclei in favor of isolated and in vitro cultivated mesothelial cells. Moreover, we found morphological differences in cell and tissue architecture. Whereas ECM by definition occurs exclusively extracellularly ECM-like spectral components were located in the perinuclear (e.g., as location of collagen synthesis) as well as in intercellular compartments of the in vitro cultured mesothelial cells ECM spectra in mesothelial cryosections (especially assigned to collagen, e.g., $818,1453 \mathrm{~cm}^{-1}$ ) seemed to be for the most located in the extracellular space. For both samples, lipids (e.g., 1774, $2852,1369,1076 \mathrm{~cm}^{-1}$ ) were found intracellular and perinuclear. Overall, using PCA, the biochemical information of in vitro cultured mesothelial cells and mesothelial cryosections tended to differ (Figure 4c,d); however, the identified differences in DNA/nuclei (e.g., 1095, $788 \mathrm{~cm}^{-1}$ ) and in lipid components (differences in $\mathrm{CH} 2$ and $\mathrm{C}=\mathrm{C}$ molecular vibrations) were not statistically significant for any of the evaluated PCs (Figure 4g,h). Remarkably, and in comparison with the mesothelial layer of cryofixed peritoneum, the molecular Raman signatures of nuclei and lipids of in vitro cultured mesothelial cells were highly consistent, represented by a nominal standard division (SD), even though the Raman data were obtained from three independent patients.

It is widely recognized that $3 \mathrm{D}$ microenvironments alter gene expression, cell plasticity and differentiation of different tissues, i.e., physical cues among others [55]. Isolated primary human peritoneal mesothelial cells from PWC enable further studies on cellular microenvironment, mechanotransduction and thereby induced cellular regulation processes as mechanical forces are crucial factors of peritoneal functionality in light of permanent organ movement and peristalsis. 
In conclusion, we demonstrate an innovative and efficient method to isolate primary human peritoneal mesothelial cells from PWC. This outstanding purity and morphological and molecular stability over several passages is a great advantage to use the patient-specific cells in standard in vitro as well in advanced 3D and microfluidic, in vivo-like cell culture models to improve the understanding of the development of peritoneal diseases.

\section{Conclusions}

Isolation of primary human mesothelial cells from laparoscopic PWC enables the ethically sound generation of capable, patient-derived 2D cell cultures without increased invasiveness. Due to the high purity of the mesothelial cell population, the established methodology could significantly simplify the development of next generation in vitro models and increase the validity and reproducibility of research on peritoneal diseases and treatment strategies.

Supplementary Materials: The following are available online at https:/ /www.mdpi.com/2227-905 9/9/2/176/s1, Figure S1: Distinction of co-cultured PWC-derived mesothelial cells and peritoneal fibroblasts by IF-staining with cytokeratin and fibronectin, Figure S2: Gating strategies of abdominal wash cytology-derived mesothelial cells and peritoneal fibroblasts. Figure S3: Cytokeratin staining and flow cytometry of KC and BJ fibroblasts.

Author Contributions: Conceptualization, M.W.; data curation, M.H.; formal analysis, M.H., L.B. and M.W.; funding acquisition, S.Y.B., K.S.-L. and M.W.; investigation, M.W.; methodology, M.H., L.B., A.-L.K., N.F., J.M., D.A.C.B., P.J., F.N., J.P.-F., B.K. and M.W.; resources, S.Y.B., K.S.-L. and B.K.; supervision, M.W.; validation, L.B., A.-L.K., N.F., J.M. and D.A.C.B.; writing-original draft, M.H. and M.W. All authors have read and agreed to the published version of the manuscript.

Funding: This research was funded by the Ministry of Science, Research and the Arts of BadenWürttemberg (33-729.55-3/214, 01/2015 and SI-BW 01222-91, 08/2011 to K.S.-L.), the German Research Foundation (INST 2388/34-1, 5/2013, INST 2388/64-1, 01/2017 to K.S.-L.), and the Graduate School 2543/1 "Intraoperative Multi-Sensory Tissue-Differentiation in Oncology" (project(s) A3 and C2) funded by the German Research Foundation (GRK 2543/1 to S.Y.B, K.S.-L., M.W.; 04/2020).

Institutional Review Board Statement: The study was conducted according to the guidelines of the Declaration of Helsinki, and approved by the Institutional Ethics Committee of the Medical Faculty of the University of Tübingen (protocol codes 649-2017BO2, approval: 12.01.2018 and 495/2018BO2, approval: 19.10.2018).

Informed Consent Statement: Informed consent was obtained from all subjects involved in the study. Written informed consent has been obtained from the patients to publish this paper.

Data Availability Statement: The data presented in this study are available on request from the corresponding author. The data are not publicly available due to the ongoing character of the entire research project.

Acknowledgments: We acknowledge support by Open Access Publishing Fund of the University of Tübingen. The work described in this paper was conducted in the framework of the Graduate School 2543/1 "Intraoperative Multi-Sensory Tissue-Differentiation in Oncology" (project(s) A3 and C2) funded by the German Research Foundation (DFG-Deutsche Forschungsgemeinschaft).

Conflicts of Interest: The authors declare no conflict of interest.

\section{References}

1. Herrick, S.E.; Mutsaers, S.E. Mesothelial progenitor cells and their potential in tissue engineering. Int. J. Biochem. Cell Biol. 2004, 36, 621-642. [CrossRef] [PubMed]

2. Mutsaers, S.E.; Prêle, C.M.-A.; Pengelly, S.; Herrick, S.E. Mesothelial cells and peritoneal homeostasis. Fertil. Steril. 2016, 106, 1018-1024. [CrossRef]

3. Mutsaers, S.E. The mesothelial cell. Int. J. Biochem. Cell Biol. 2004, 36, 9-16. [CrossRef]

4. Capobianco, A.; Cottone, L.; Monno, A.; Manfredi, A.A.; Rovere-Querini, P. The peritoneum: Healing, immunity, and diseases. J. Pathol. 2017, 243, 137-147. [CrossRef]

5. Whitaker, D.; Papadimitriou, J. Mesothelial healing: Morphological and kinetic investigations. J. Pathol. 1985, 145, 159-175. [CrossRef] 
6. Dauleh, S.; Santeramo, I.; Fielding, C.; Ward, K.; Herrmann, A.; Murray, P.; Wilm, B. Characterisation of Cultured Mesothelial Cells Derived from the Murine Adult Omentum. PLoS ONE 2016, 11, e0158997. [CrossRef]

7. Fischer, A.; Koopmans, T.; Ramesh, P.; Christ, S.; Strunz, M.; Wannemacher, J.; Aichler, M.; Feuchtinger, A.; Walch, A.; Ansari, M.; et al. Post-surgical adhesions are triggered by calcium-dependent membrane bridges between mesothelial surfaces. Nat. Commun. 2020, 11, 3068. [CrossRef]

8. Lee, H.B.; Ha, H. Mechanisms of epithelial-mesenchymal transition of peritoneal mesothelial cells during peritoneal dialysis. J. Korean Med. Sci. 2007, 22, 943-945. [CrossRef]

9. van Baal, J.O.; Van de Vijver, K.K.; Nieuwland, R.; van Noorden, C.J.; van Driel, W.J.; Sturk, A.; Kenter, G.G.; Rikkert, L.G.; Lok, C.A. The histophysiology and pathophysiology of the peritoneum. Tissue Cell 2017, 49, 95-105. [CrossRef] [PubMed]

10. van Hinsbergh, V.W.; Kooistra, T.; Scheffer, M.A.; Hajo van Bockel, J.; van Muijen, G.N. Characterization and fibrinolytic properties of human omental tissue mesothelial cells. Comparison with endothelial cells. Blood 1990, 75, 1490-1497. [CrossRef]

11. Stylianou, E.; Jenner, L.A.; Davies, M.; Coles, G.A.; Williams, J.D. Isolation, culture and characterization of human peritoneal mesothelial cells. Kidney Int. 1990, 37, 1563-1570. [CrossRef]

12. Yung, S.; Li, F.K.; Chan, T.M. Peritoneal Mesothelial Cell Culture and Biology. Perit. Dial. Int. 2006, 26, 162-193. [CrossRef]

13. Pronk, A.; Leguit, P.; Hoynck van Papendrecht, A.A.G.M.; Hagelen, E.; van Vroonhoven, T.J.M.V.; Verbrugh, H.A. A cobblestone cell isolated from the human omentum: The mesothelial cell; isolation, identification, and growth characteristics. In Vitro Cell. Dev. Biol. Anim. 1993, 29, 127-134. [CrossRef]

14. Yamamoto, T.; Izumotani, T.; Otoshi, T.; Kim, M. Morphological studies of mesothelial cells in CAPD effluent and their clinical significance. Am. J. Kidney Dis. 1998, 32, 946-952. [CrossRef]

15. Chan, T.M.; Leung, J.K.H.; Sun, Y.; Lai, K.N.; Tsang, R.C.W.; Yung, S. Different effects of amino acid-based and glucose-based dialysate from peritoneal dialysis patients on mesothelial cell ultrastructure and function. Nephrol. Dial. Transplant. 2003, 18, 1086-1094. [CrossRef]

16. Takashima, A. Establishment of Fibroblast Cultures. Curr. Protoc. Cell Biol. 1998, 2.1.1-2.1.12. [CrossRef]

17. Wenzel, T.; Carvajal Berrio, D.A.; Daum, R.; Reisenauer, C.; Weltmann, K.-D.; Wallwiener, D.; Brucker, S.Y.; Schenke-Layland, K.; Brauchle, E.-M.; Weiss, M. Molecular Effects and Tissue Penetration Depth of Physical Plasma in Human Mucosa Analyzed by Contact- and Marker-Independent Raman Microspectroscopy. ACS Appl. Mater. Interfaces 2019, 11, 42885-42895. [CrossRef]

18. Wenzel, T.; Carvajal Berrio, D.A.; Reisenauer, C.; Layland, S.; Koch, A.; Wallwiener, D.; Brucker, S.Y.; Schenke-Layland, K.; Brauchle, E.M.; Weiss, M. Trans-Mucosal Efficacy of Non-Thermal Plasma Treatment on Cervical Cancer Tissue and Human Cervix Uteri by a Next Generation Electrosurgical Argon Plasma Device. Cancers 2020, 12, 267. [CrossRef]

19. Notingher, I.; Green, C.; Dyer, C.; Perkins, E.; Hopkins, N.; Lindsay, C.; Hench, L.L. Discrimination between ricin and sulphur mustard toxicity in vitro using Raman spectroscopy. J. R. Soc. Interface 2004, 1, 79-90. [CrossRef]

20. Malini, R.; Venkatakrishna, K.; Kurien, J.; Pai, K.M.; Rao, L.; Kartha, V.B.; Krishna, C.M. Discrimination of normal, inflammatory, premalignant, and malignant oral tissue: A Raman spectroscopy study. Biopolymers 2006, 81, 179-193. [CrossRef]

21. Hanlon, E.B.; Manoharan, R.; Koo, T.W.; Shafer, K.E.; Motz, J.T.; Fitzmaurice, M.; Kramer, J.R.; Itzkan, I.; Dasari, R.R.; Feld, M.S. Prospects for in vivo Raman spectroscopy. Phys. Med. Biol. 2000, 45, R1-R59. [CrossRef]

22. Dukor, R.K. Vibrational Spectroscopy in the Detection of Cancer. In Handbook of Vibrational Spectroscopy; John Wiley \& Sons: Hoboken, NJ, USA, 2001. [CrossRef]

23. Kline, N.J.; Treado, P.J. Raman Chemical Imaging of Breast Tissue. J. Raman Spectrosc. 1997, 28, 119-124. [CrossRef]

24. Koljenović, S.; Schut, T.B.; Vincent, A.; Kros, J.M.; Puppels, G.J. Detection of Meningioma in Dura Mater by Raman Spectroscopy. Anal. Chem. 2005, 77, 7958-7965. [CrossRef]

25. Lau, D.P.; Huang, Z.; Lui, H.; Man, C.S.; Berean, K.; Morrison, M.D.; Zeng, H. Raman spectroscopy for optical diagnosis in normal and cancerous tissue of the nasopharynx-preliminary findings. Lasers Surg. Med. 2003, 32, 210-214. [CrossRef]

26. Jyothi Lakshmi, R.; Kartha, V.B.; Murali Krishna, C.; JG, R.S.; Ullas, G.; Uma Devi, P. Tissue Raman spectroscopy for the study of radiation damage: Brain irradiation of mice. Radiat. Res. 2002, 157, 175-182. [CrossRef]

27. Frank, C.J.; McCreery, R.L.; Redd, D.C. Raman spectroscopy of normal and diseased human breast tissues. Anal. Chem. 1995, 67, 777-783. [CrossRef] [PubMed]

28. Cheng, W.T.; Liu, M.T.; Liu, H.N.; Lin, S.Y. Micro-Raman spectroscopy used to identify and grade human skin pilomatrixoma. Microsc. Res. Tech. 2005, 68, 75-79. [CrossRef]

29. Shetty, G.; Kendall, C.; Shepherd, N.; Stone, N.; Barr, H. Raman spectroscopy: Elucidation of biochemical changes in carcinogenesis of oesophagus. Br. J. Cancer 2006, 94, 1460-1464. [CrossRef] [PubMed]

30. Viehoever, A.R.; Anderson, D.; Jansen, D.; Mahadevan-Jansen, A. Organotypic raft cultures as an effective in vitro tool for understanding Raman spectral analysis of tissue. Photochem. Photobiol. 2003, 78, 517-524. [CrossRef]

31. Stone, N.; Kendall, C.; Smith, J.; Crow, P.; Barr, H. Raman spectroscopy for identification of epithelial cancers. Faraday Discuss. 2004, 126, 141-157. [CrossRef]

32. Huang, Z.; McWilliams, A.; Lui, H.; McLean, D.I.; Lam, S.; Zeng, H. Near-infrared Raman spectroscopy for optical diagnosis of lung cancer. Int. J. Cancer 2003, 107, 1047-1052. [CrossRef]

33. Naumann, D. Infrared and NIR Raman Spectroscopy in Medical Microbiology. In Proceedings of the BiOS '98 International Biomedical Optics Symposium, San Jose, CA, USA, 27 January 1998; SPIE: London, UK, 1998; Volume 3257. 
34. Schulz, H.; Baranska, M. Identification and quantification of valuable plant substances by IR and Raman spectroscopy. Vib. Spectrosc. 2007, 43, 13-25. [CrossRef]

35. Liu, F.Y.; Duan, S.B.; Long, Z.G. Culture and characterization of human peritoneal mesothelial cells. Hunan Yi Ke Da Xue Xue Bao 2001, 26, 321-324. [PubMed]

36. Fang, C.C.; Yen, C.J.; Chen, Y.M.; Shyu, R.S.; Tsai, T.J.; Lee, P.H.; Hsieh, B.S. Pentoxifylline inhibits human peritoneal mesothelial cell growth and collagen synthesis: Effects on TGF-beta. Kidney Int. 2000, 57, 2626-2633. [CrossRef] [PubMed]

37. Fang, C.-C.; Huang, J.-W.; Shyu, R.-S.; Yen, C.-J.; Shiao, C.-H.; Chiang, C.-K.; Hu, R.-H.; Tsai, T.-J. Fibrin-Induced Epithelialto-Mesenchymal Transition of Peritoneal Mesothelial Cells as a Mechanism of Peritoneal Fibrosis: Effects of Pentoxifylline. PLoS ONE 2012, 7, e44765. [CrossRef] [PubMed]

38. Chung-Welch, N.; Patton, W.F.; Shepro, D.; Cambria, R.P. Human omental microvascular endothelial and mesothelial cells: Characterization of two distinct mesodermally derived epithelial cells. Microvasc. Res. 1997, 54, 108-120. [CrossRef]

39. Rayner, S.G.; Zheng, Y. Engineered Microvessels for the Study of Human Disease. J. Biomech. Eng. 2016, 138, 1108011-11080111. [CrossRef]

40. Fang, C.C.; Yen, C.J.; Chen, Y.M.; Chu, T.S.; Lin, M.T.; Yang, J.Y.; Tsai, T.J. Diltiazem suppresses collagen synthesis and IL-1betainduced TGF-beta1 production on human peritoneal mesothelial cells. Nephrol. Dial. Transplant. 2006, 21, 1340-1347. [CrossRef] [PubMed]

41. Yáñez-Mó, M.; Lara-Pezzi, E.; Selgas, R.; Ramírez-Huesca, M.; Domínguez-Jiménez, C.; Jiménez-Heffernan, J.A.; Aguilera, A.; Sánchez-Tomero, J.A.; Bajo, M.A.; Álvarez, V.; et al. Peritoneal Dialysis and Epithelial-to-Mesenchymal Transition of Mesothelial Cells. N. Engl. J. Med. 2003, 348, 403-413. [CrossRef]

42. Makin, C.A.; Bobrow, L.G.; Bodmer, W.F. Monoclonal antibody to cytokeratin for use in routine histopathology. J. Clin. Pathol. 1984, 37, 975. [CrossRef]

43. Von Koskull, H.; Virtanen, I. Induction of cytokeratin expression in human mesenchymal cells. J. Cell. Physiol. 1987, 133, 321-329. [CrossRef]

44. Moll, R.; Franke, W.W.; Schiller, D.L.; Geiger, B.; Krepler, R. The catalog of human cytokeratins: Patterns of expression in normal epithelia, tumors and cultured cells. Cell 1982, 31, 11-24. [CrossRef]

45. Yang, A.H.; Chen, J.Y.; Lin, J.K. Myofibroblastic conversion of mesothelial cells. Kidney Int. 2003, 63, 1530-1539. [CrossRef]

46. Lugli, A.; Forster, Y.; Haas, P.; Nocito, A.; Bucher, C.; Bissig, H.; Mirlacher, M.; Storz, M.; Mihatsch, M.J.; Sauter, G. Calretinin expression in human normal and neoplastic tissues: A tissue microarray analysis on 5233 tissue samples. Hum. Pathol. 2003, 34, 994-1000. [CrossRef]

47. Betjes, M.G.; Bos, H.J.; Krediet, R.T.; Arisz, L. The mesothelial cells in CAPD effluent and their relation to peritonitis incidence. Perit. Dial. Int. 1991, 11, 22-26. [CrossRef]

48. Harvey, W.; Amlot, P.L. Collagen production by human mesothelial cells in vitro. J. Pathol. 1983, 139, 337-347. [CrossRef]

49. Fetsch, P.A.; Simsir, A.; Abati, A. Comparison of antibodies to HBME-1 and calretinin for the detection of mesothelial cells in effusion cytology. Diagn. Cytopathol. 2001, 25, 158-161. [CrossRef] [PubMed]

50. Czernobilsky, B.; Moll, R.; Levy, R.; Franke, W.W. Co-expression of Cytokeratin and Vimentin Filaments in Mesothelial, Granulosa and Rete Ovarii Cells of the Human Ovary. Eur. J. Cell Biol. 1985, 37, 175-190.

51. Marzi, J.; Brauchle, E.M.; Schenke-Layland, K.; Rolle, M.W. Non-invasive functional molecular phenotyping of human smooth muscle cells utilized in cardiovascular tissue engineering. Acta Biomater. 2019, 89, 193-205. [CrossRef]

52. Brauchle, E.; Schenke-Layland, K. Raman spectroscopy in biomedicine-Non-invasive in vitro analysis of cells and extracellular matrix components in tissues. Biotechnol. J. 2013, 8, 288-297. [CrossRef]

53. Parlatan, U.; Inanc, M.T.; Ozgor, B.Y.; Oral, E.; Bastu, E.; Unlu, M.B.; Basar, G. Raman spectroscopy as a non-invasive diagnostic technique for endometriosis. Sci. Rep. 2019, 9, 19795. [CrossRef]

54. Gaifulina, R.; Maher, A.T.; Kendall, C.; Nelson, J.; Rodriguez-Justo, M.; Lau, K.; Thomas, G.M. Label-free Raman spectroscopic imaging to extract morphological and chemical information from a formalin-fixed, paraffin-embedded rat colon tissue section. Int. J. Exp. Pathol. 2016, 97, 337-350. [CrossRef]

55. Frtús, A.; Smolková, B.; Uzhytchak, M.; Lunova, M.; Jirsa, M.; Hof, M.; Jurkiewicz, P.; Lozinsky, V.I.; Wolfová, L.; Petrenko, Y.; et al. Hepatic Tumor Cell Morphology Plasticity under Physical Constraints in 3D Cultures Driven by YAP-mTOR Axis. Pharmaceuticals 2020, 13, 430. [CrossRef] 